\title{
Prognostic significance of B-cell lymphoma 2 expression in acute leukemia: A systematic review and meta-analysis
}

\author{
YANFENG LIU, PENGCHENG HE, FENG LIU, LILI SHI, HUACHAO ZHU, \\ XIAOYAN CHENG, JING ZHAO, YUAN WANG and MEI ZHANG \\ Department of Hematology, The First Affiliated Hospital, School of Medicine, \\ Xi'an Jiaotong University, Xi'an, Shaanxi 710061, P.R. China
}

Received June 14, 2013; Accepted January 8, 2014

DOI: $10.3892 / \operatorname{mco} .2014 .248$

\begin{abstract}
A number of studies have provided estimates of the correlation between B-cell lymphoma 2 (Bcl-2) expression and its clinical significance in acute leukemia (AL); however, the results have been heterogeneous. In order to clarify the prognostic significance of Bcl-2 status in patients with AL, a systematic review and meta-analysis of 5 published studies including a total of 665 subjects was performed. The reported frequency of Bcl-2 expression was 0-99.00\%. Bcl-2-positive patients had a higher median white blood cell count compared to $\mathrm{Bcl}-2$-negative patients. Additionally, Bcl-2-negative patients had $>2$-fold higher odds of achieving complete remission (CR) compared to Bcl-2-positive patients. The summary hazard ratio of Bcl-2 negativity/positivity for $\mathrm{CR}$ was 0.62 [95\% confidence interval: $0.53-0.81, \mathrm{P}<0.001]$. Although this meta-analysis was based on data abstracted from observational studies, our results may justify the use of risk-adapted therapeutic strategies for AL according to the $\mathrm{Bcl}-2$ expression status.
\end{abstract}

\section{Introduction}

Acute leukemia (AL) is a heterogeneous group of disorders that result from clonal transformation of hematopoietic precursors through the acquisition of chromosomal rearrangements and multiple gene mutations (1). It was reported that AL accounts for $\sim 20,000$ cancer diagnoses and 10,000 deaths annually in the United States (2). However, the pathogenesis of the majority of AL cases remains unknown. Cytogenetic aberrations and molecular genetic alterations are currently considered

Correspondence to: Dr Pengcheng He or Dr Mei Zhang, Department of Hematology, The First Affiliated Hospital, School of Medicine, Xi'an Jiaotong University, 277 Yanta West Road, Xi'an, Shaanxi 710061, P.R. China

E-mail: hepc@163.com

E-mail: zhangmei@medmail.com.cn

Key words: acute leukemia, B-cell lymphoma 2 protein, clinical significance, meta-analysis to be the most significant prognostic factors in determining the response to chemotherapy and survival outcome $(3,4)$. The analysis and characterization of the genes and proteins involved in leukemia development at the molecular level may enhance our knowledge of potential prognostic factors. These factors may be roughly divided into tumor suppressor genes, proto-oncogenes and markers of metastatic propensity and proliferation (5).

The B-cell lymphoma 2 (Bcl-2) protein is located in the mitochondrial and nuclear membranes and the endoplasmic reticulum $(6,7)$. It was demonstrated that $\mathrm{Bcl}-2$ is able to prevent multi-factor-mediated apoptosis and its expression status may determine cell survival and death. The Bcl-2 protein has been identified in a number of tumor cells, including lymphoma (8), breast cancer (9), prostate cancer (10) and neuroblastoma cells (11) and the Bcl-2 expression status in AL has been a focus of investigation. However, results regarding the association between $\mathrm{Bcl}-2$ expression and its clinical significance in AL are heterogeneous. Therefore, the aim of the present systematic review and meta-analysis was to assess the prognostic value of $\mathrm{Bcl}-2$ expression in patients with AL.

\section{Materials and methods}

Publication selection. Studies eligible for inclusion in this meta-analysis met the following criteria: i) published up to December, 2012 as original articles written in English; ii) included only AL patients; iii) measured Bcl-2 expression (protein, DNA or RNA); and iv) provided survival data according to Bcl-2 status, including complete remission (CR), disease-free survival and/or overall survival. Studies were excluded if they focused exclusively on acute promyelocytic leukemia. Multiple reports of a single study were considered as one publication and only the most recent article was included.

Methodological assessment. A computerized literature search of PubMed, Medline and EMBASE databases was conducted using the terms 'acute leukemia', Bcl-2' and 'survival'. The publication period was limited to before December, 2012 and the language was limited to English. The initial search yielded a total of 53 publications. After reviewing the titles and abstracts of these publications, 37 were excluded, leaving 16 as candidate articles. Of these, 11 full-text articles were excluded 
Table I. Studies included in the meta-analysis.

\begin{tabular}{llrrr}
\hline Authors & Country & $\begin{array}{r}\text { No. of } \\
\text { subjects }\end{array}$ & $\begin{array}{c}\text { Bcl-2 } \\
\text { expression } \\
(\%)\end{array}$ & Refs. \\
\hline Zhao et al & China & 41 & $5.5-52.4$ & $(18)$ \\
Campos et al & France & 82 & $0-95.0$ & $(19)$ \\
Karakas et al & Germany & 156 & $0-95.0$ & $(20)$ \\
Uckun et al & USA & 338 & $0-61.2$ & $(21)$ \\
Maung et al & UK & 48 & $1.0-99.0$ & $(22)$ \\
\hline
\end{tabular}

due to lack of survival data. A total of 5 studies met the eligibility criteria and were finally included in this meta-analysis (Table I). The process of study selection is shown in Fig. 1.

To avoid bias in the data abstraction process, two co-authors (Mei Zhang and Pengcheng $\mathrm{He}$ ) independently examined the data from the articles and subsequently compared the results. All the data were assessed for internal consistency and disagreements were resolved through discussion. The characteristics abstracted from the articles included last name of first author, year of publication, location of the study, number of subjects, mean or median values of white blood cell (WBC) count, incidence of Bcl-2 expression, outcome, including hematological CR rate, hazard ratio (HR) and $95 \%$ confidence interval (CI) for $\mathrm{CR}$ according to the Bcl-2 status, based on multivariate analysis. When the data required for the analysis could not be abstracted, attempts were made to contact the investigators who conducted the studies.

The quality of evidence and the strength of recommendations were evaluated by GRADEprofiler software, version 3.2 (http:// ims.cochrane.org) (12). Any discrepancies in quality assessments were resolved by consensus amongst authors. The overall quality of the evidence was graded as moderate.

Quantitative data synthesis. The HR was used to assess the effect of Bcl-2-negative status compared to that of Bcl-2-positive status on AL patient survival. The natural logarithm of a crude HR and its variance within the study was calculated using the abstracted survival probabilities at each time point with the methods proposed by Parmar et al (13) as previously described (14). The HR was calculated to compare the probability of survival failure between Bcl-2-negative and Bcl-2-positive patients; an HR of $<1$ indicated that the Bcl-2-negative status yielded a higher survival rate compared to the Bcl-2-positive status.

A DerSimonian-Laird random method was used to calculate summary HRs and their 95\% CIs. Begg's funnel plots (15) and Egger's test (16) were used to detect possible publication bias. The between-study variation $\left(\tau^{2}\right)$ from the $\mathrm{Q}$ statistic (17) was also calculated.

Statistical analysis. All the statistical analyses were conducted with Stata 12 software (StataCorp, College Station, TX, USA). $\mathrm{P}<0.05$ was considered to indicate a statistically significant difference for a summary HR. To avoid false-negative results due to the small number of studies entered in the regression analysis, $\mathrm{P}<0.15$ was defined as significant for a

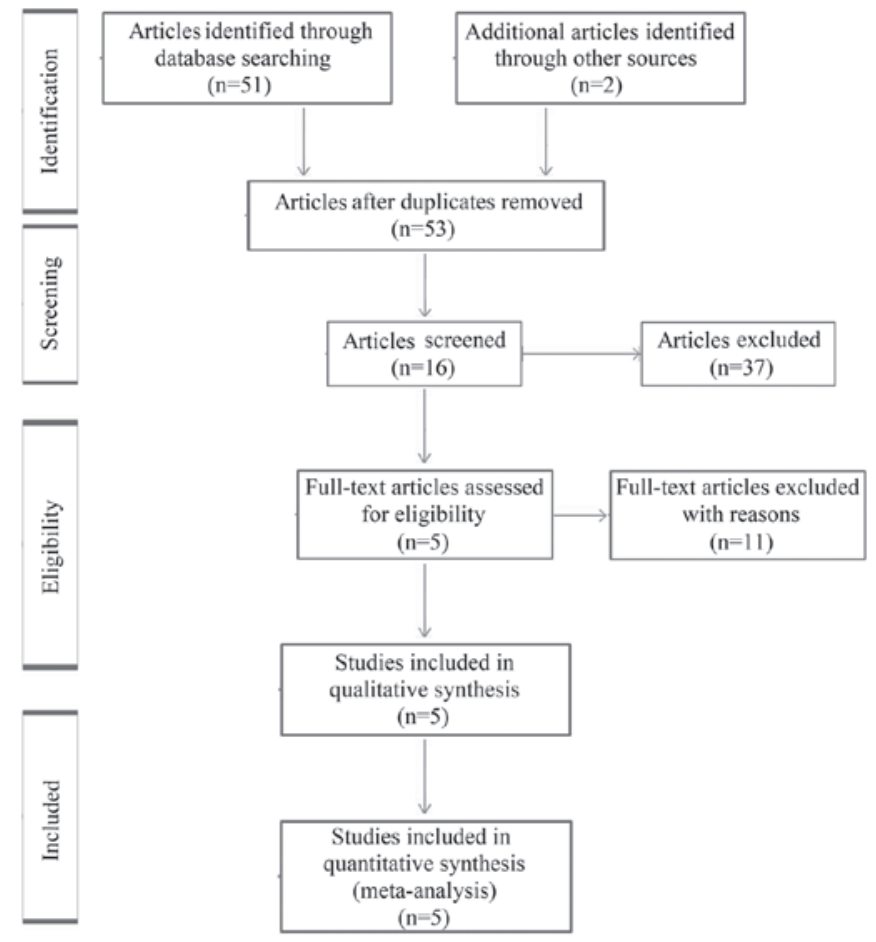

Figure 1. Flow diagram of the study selection process.

meta-regression test. No adjustment of multiple comparisons was performed due to the lack of statistical power of the study and the existence of an a priori hypothesis.

\section{Results}

Study selection and characteristics. A total of 5 studies, including a total of 665 subjects (235 with positive and 433 with negative Bcl-2 expression) were finally included in our meta-analysis (Table I). The studies originated from China (18), France (19), Germany (20), the United States (21) and the United Kingdom (22). Immunohistochemical analysis, flow cytometry or reverse transcription-polymerase chain reaction were used in all the trials to detect the expression of $\mathrm{Bcl}-2$ protein or mRNA. The frequency of Bcl-2 expression in AL patients varied between 0 and $99.00 \%$. There was no graphical or statistical evidence of publication bias for either the WBC count or CR.

Association between Bcl-2 status and WBC count. The results of the median $\mathrm{WBC}$ count according to $\mathrm{Bcl}-2$ expression status in the different studies are summarized in Table II. In total, 461 of the 665 subjects (69.32\%) revealed that the positive Bcl-2 expression status was associated with a higher median WBC count compared to the negative Bcl-2 expression status (three studies were considered evaluable for meta-analysis).

Survival analysis. The results of the survival analysis are presented in Table III. In total, 327 of the 665 subjects $(49.17 \%)$ indicated that positive Bcl-2 expression was a poor prognostic factor for survival (all 5 studies were evaluable for meta-analysis) and 338 subjects (50.83\%) indicated that $\mathrm{Bcl}-2$ 
Table II. Median WBC count according to Bcl-2 status.

\begin{tabular}{llccc}
\hline Authors & $\begin{array}{c}\text { Bcl-2 } \\
\text { status }\end{array}$ & $\begin{array}{c}\text { No. of } \\
\text { subjects }\end{array}$ & $\begin{array}{c}\text { Median WBC } \\
\text { count }\left(10^{9} / 1\right)\end{array}$ & Refs. \\
\hline Zhao et al & Positive & 14 & $50.24 \pm 31.09^{\mathrm{a}}$ & $(18)$ \\
& Negative & 27 & $17.45 \pm 5.95$ & \\
Campos et al & Positive & 28 & $105.28 \pm 28.46^{\mathrm{a}}$ & $(19)$ \\
& Negative & 54 & $44.85 \pm 6.30$ & \\
Uckun et al & Positive & 93 & $73.44 \pm 20.69^{\mathrm{a}}$ & $(21)$ \\
& Negative & 245 & $20.38 \pm 8.16$ & \\
\hline
\end{tabular}

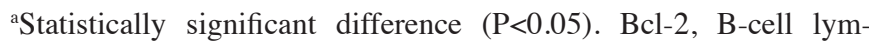
phoma 2; WBC, white blood cell.

Table III. Complete remission according to Bcl-2 status.

\begin{tabular}{|c|c|c|c|c|}
\hline Authors & $\begin{array}{l}\text { Bcl-2 } \\
\text { status }\end{array}$ & $\begin{array}{c}\text { No. of } \\
\text { subjects }\end{array}$ & $\begin{array}{c}\text { Complete } \\
\text { remission } \\
(\%)\end{array}$ & Refs \\
\hline \multirow[t]{2}{*}{ Zhao et al } & Positive & 14 & $0^{\mathrm{a}}$ & \multirow[t]{2}{*}{ (18) } \\
\hline & Negative & 27 & 85.71 & \\
\hline \multirow[t]{2}{*}{ Campos et al } & Positive & 28 & $28.57^{\mathrm{a}}$ & \multirow[t]{2}{*}{ (19) } \\
\hline & Negative & 54 & 85.19 & \\
\hline \multirow[t]{2}{*}{ Karakas et al } & Positive & 61 & $33.01^{\mathrm{a}}$ & \multirow[t]{2}{*}{ (20) } \\
\hline & Negative & 95 & 67.43 & \\
\hline \multirow[t]{2}{*}{ Uckun et al } & Positive & 93 & 67.60 & \multirow[t]{2}{*}{$(21)$} \\
\hline & Negative & 245 & 70.50 & \\
\hline \multirow[t]{2}{*}{ Maung et al } & Positive & 39 & $46.51^{\mathrm{a}}$ & \multirow[t]{2}{*}{ (22) } \\
\hline & Negative & 9 & 77.78 & \\
\hline
\end{tabular}

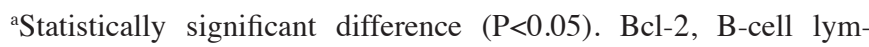
phoma 2.

expression was not a prognostic factor for survival (all 5 studies were evaluable for meta-analysis). The summary $\mathrm{HR}$ of $\mathrm{Bcl}-2$ negativity/positivity for CR was 0.62 (95\% CI: 0.53-0.81, $\mathrm{P}<0.001)$. The test for heterogeneity, which evaluates the variation in study outcomes among studies in a meta-analysis, revealed no significant heterogeneity among the studies included in the $\mathrm{CR}$ analysis $\left(\mathrm{Q}=4.06, \mathrm{df}=3, \mathrm{P}=0.36, \tau^{2}=24\right)$ (Figs. 2 and 3).

Furthermore, we conducted a sensitivity test during this meta-analysis. The exclusion of any single study did not affect the overall results in any way.

\section{Discussion}

The prognostic significance of Bcl-2 expression in patients with AL was previously investigated, with some results suggesting a positive prognostic effect of Bcl-2 (23) and others reporting no differences in clinical outcome between patients with and those without Bcl-2 expression (21). The aim of the present systematic review and meta-analysis was to elucidate the prognostic significance of the $\mathrm{Bcl}-2$ status in patients with AL. A meta-analysis is a statistical method used for integrating

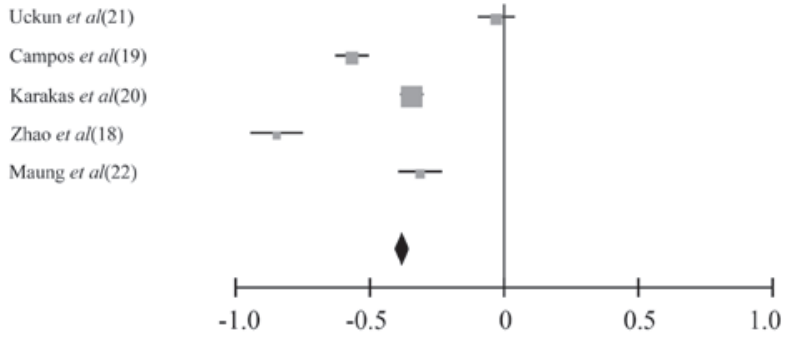

Figure 2. Forest plots of the hazard ratio (HR) for complete remission. The size of the blocks or diamonds reflects the weight for the random-effects model in the meta-analysis. HR $<1$ indicates that the negative expression of Bcl-2 was associated with a better prognosis. Bcl-2, B-cell lymphoma 2; WBC, white blood cell.

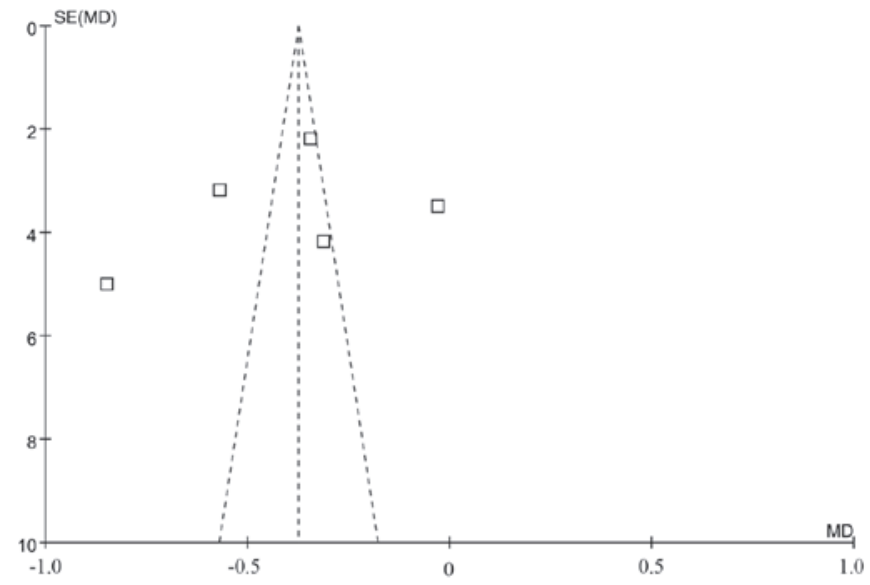

Figure 3. Funnel plot of the hazard ratio for complete remission. SE (MD), standard error of the mean difference.

results from independent studies for a specified outcome. Combining relevant studies increases the statistical power and enables the detection of effects that may be overlooked by individual studies (24). The present meta-analysis reported that the frequency of Bcl-2 expression was $0-99.00 \%$ in the 5 selected studies. Bcl-2-positive patients had a higher median WBC count compared to Bcl-2-negative patients. Additionally, Bcl-2-negative patients had $>2$-fold higher odds of achieving CR compared to Bcl-2-positive patients. The summary HR of Bcl-2 negativity/positivity for CR was 0.62 (95\% CI: 0.53-0.81, $\mathrm{P}<0.001)$.

There were several limitations to our study. First, the analyses were based on observational rather than prospective controlled studies or randomized trials. Second, we used abstracted data, whereas an individual patient data-based meta-analysis may have provided a more robust estimate of the association. Therefore, our results should be interpreted with caution by clinical physicians. In addition, as is often the case with meta-analyses, the significant effect of heterogeneity requires consideration. Although gender and age at the time of diagnosis were not identified as sources of heterogeneity, we cannot exclude the potential effects of other factors, such as differences in treatment and distinct cytogenetic categories, which were not investigated in our analysis. Finally, publication bias, although not directly detected, may have also affected the accuracy of our results $(17,25)$. 
Despite the abovementioned limitations, our meta-analysis demonstrated that Bcl-2 expression exerts a poor effect on the survival outcome of AL patients. Our findings suggest that it may be beneficial to distinguish Bcl-2-negative from Bcl-2-positive AL and justify the use of risk-adapted therapeutic strategies for AL based on the $\mathrm{Bcl}-2$ expression status.

Further prospective studies should include a large number of patients in order to reach more definitive conclusions. In addition to the presence or absence of $\mathrm{Bcl}-2$ expression, several factors associated with Bcl-2 were suggested as being of prognostic value, including the expression levels of CD34 transcripts and the expression status of other Bcl family members. These factors require further investigation in order to achieve a more accurate estimation of the prognosis of AL.

\section{Acknowledgements}

This study was supported by grants from the Fundamental Research Funds for the Central Universities and the Shaanxi Province Science and Technology Development Fund, China (nos. 2010K01-135 and 2012KTCL03-12).

\section{References}

1. Rubnitz JE, Gibson B and Smith FO: Acute myeloid leukemia. Hematol Oncol Clin North Am 24: 35-63, 2010.

2. Jemal A, Siegel R, Xu J and Ward E: Cancer statistics, 2010. CA Cancer J Clin 60: 277-300, 2010.

3. Harrison CJ, Hills RK, Moorman AV, et al: Cytogenetics of childhood acute myeloid leukemia: United Kingdom Medical Research Council Treatment trials AML 10 and 12. J Clin Oncol 28: 2674-2681, 2010.

4. Grimwade D: The clinical significance of cytogenetic abnormalities in acute myeloid leukaemia. Best Pract Res Clin Haematol 14: 497-529, 2001.

5. Martin B, Paesmans M, Berghmans T, et al: Role of Bcl-2 as a prognostic factor for survival in lung cancer: a systematic review of the literature with meta-analysis. Br J Cancer 89: 55-64, 2003

6. Leber B, Lin J and Andrews DW: Still embedded together binding to membranes regulates $\mathrm{Bcl}-2$ protein interactions. Oncogene 29: 5221-5230, 2010.

7. Chipuk JE, Moldoveanu T, Llambi F, Parsons MJ and Green DR: The BCL-2 family reunion. Mol Cell 37: 299-310, 2010.

8. Adams JM and Cory S: The Bcl-2 apoptotic switch in cancer development and therapy. Oncogene 26: 1324-1337, 2007.

9. Soundararajan S, Chen W, Spicer EK, Courtenay-Luck N and Fernandes DJ: The nucleolin targeting aptamer AS1411 destabilizes Bcl-2 messenger RNA in human breast cancer cells. Cancer Res 68: 2358-2365, 2008.
10. Khor LY, Moughan J, Al-Saleem T, et al: Bcl-2 and Bax expression predict prostate cancer outcome in men treated with androgen deprivation and radiotherapy on radiation therapy oncology group protocol 92-02. Clin Cancer Res 13: 3585-3590, 2007.

11. Bender A, Opel D, Naumann I, et al: PI3K inhibitors prime neuroblastoma cells for chemotherapy by shifting the balance towards pro-apoptotic $\mathrm{Bcl}-2$ proteins and enhanced mitochondrial apoptosis. Oncogene 30: 494-503, 2011.

12. Guyatt GH, Oxman AD, Vist GE, et al; GRADE Working Group: GRADE: an emerging consensus on rating quality of evidence and strength of recommendations. BMJ 336: 924-926, 2008.

13. Parmar MK, Torri V and Stewart L: Extracting summary statistics to perform meta-analyses of the published literature for survival endpoints. Stat Med 17: 2815-2834, 1998.

14. Hotta K, Matsuo K, Ueoka H, Kiura K, Tabata M and Tanimoto M: Meta-analysis of randomized clinical trials comparing cisplatin to carboplatin in patients with advanced non-small-cell lung cancer. J Clin Oncol 22: 3852-3859, 2004.

15. Begg CB and Mazumdar M: Operating characteristics of a rank correlation test for publication bias. Biometrics 50: 1088-1101, 1994.

16. Egger M, Davey Smith G, Schneider M and Minder C: Bias in meta-analysis detected by a simple, graphical test. BMJ 315: 629-634, 1997.

17. Feng JH, Guo XP, Chen YY, Wang ZJ, Cheng YP and Tang YM: Prognostic significance of IDH1 mutations in acute myeloid leukemia: a meta-analysis. Am J Blood Res 2: 254-264, 2012.

18. Zhao XQ, Li GS, Guo WJ, et al: Expression of bcl-2 and bax protein and clinical significance in children with acute leukemia. Chin J Contemp Pediatr 1: 193-195, 1999 (In Chinese).

19. Campos L, Rouault JP, Sabido O, et al: High expression of bcl-2 protein in acute myeloid leukemia cells is associated with poor response to chemotherapy. Blood 81: 3091-3096, 1993.

20. Karakas T, Maurer U, Weidmann E, Miething CC, Hoelzer D and Bergmann L: High expression of bcl-2 mRNA as a determinant of poor prognosis in acute myeloid leukemia. Ann Oncol 9: 159-165, 1998.

21. Uckun FM, Yang Z, Sather H, et al: Cellular expression of antiapoptotic BCL-2 oncoprotein in newly diagnosed childhood acute lymphoblastic leukemia: a Children's Cancer Group Study. Blood 89: 3769-3777, 1997.

22. Maung ZT, MacLean FR, Reid MM, et al: The relationship between bcl-2 expression and response to chemotherapy in acute leukaemia. Br J Haematol 88: 105-109, 1994.

23. Fakler M, Loeder S, Vogler M, et al: Small molecule XIAP inhibitors cooperate with TRAIL to induce apoptosis in childhood acute leukemia cells and overcome Bcl-2-mediated resistance. Blood 113: 1710-1722, 2009.

24. Beitinjaneh A, Jang S, Roukoz H and Majhail NS: Prognostic significance of FLT3 internal tandem duplication and tyrosine kinase domain mutations in acute promyelocytic leukemia: a systematic review. Leuk Res 34: 831-836, 2010.

25. Yanada M, Matsuo K, Suzuki T, Kiyoi H and Naoe T: Prognostic significance of FLT3 internal tandem duplication and tyrosine kinase domain mutations for acute myeloid leukemia: a meta-analysis. Leukemia 19: 1345-1349, 2005. 